\title{
Constructing Karl Popper
}

How does Science Journalism Employ Literary Devices?

\author{
Harald Hornmoen
}

\begin{abstract}
In the US, a new generation of science journalists are employing narrative techniques in their writing. What are the characteristics of this journalism? Why does it employ narrative techniques?

This article attempts to give some answers to these questions by drawing on studies of science and the media. I argue that literary science journalism is predominantly cast in a characteristic semi-narrative, coinciding with what has been regarded as the main aim of this journalism: a skilled translation of abstract knowledge assumed to have been developed by scientist sources.

In a comparative analysis of profiles of scientists written by the journalist John Horgan, I contrast his texts as they first appeared in the magazine Scientific American with later versions in his book The End of Science. The analysis sheds some light on how the different media provide different frames for the journalist's literary portrayals of the scientists as well as different possibilities with regard to expressing a subjective and critical view on their scientific achievements.
\end{abstract}

Key Words: science journalism, literary journalism, narrative techniques, genre, the profile

\section{Introduction}

Is science journalism inspired by fictional literature? Are literary devices used when reporting on scientific matters? It may seem a peculiar combination, but the fact is that quite a few journalists covering scientific issues employ techniques that we normally associate with fictional literature (Anton \& McCourt 1995).

However, given the relatively widespread practice of literary science journalism, scholarly attention to the form has been rather modest. In general, literary nonfiction remains, as Barbara Lounsberry has noted, "the great unexplored territory of contemporary criticism" (Lounsberry 1990: xi). The communication scholar John Hartsock (1998) asserts that the study of journalism has historically excluded literary journalism from serious scholarly consideration. According to him, the form has existed largely outside the dominant critical paradigms of scholarship and criticism. He particularly points to how the study of journalism has moved from being a humanistic and rhetorical enterprise to being one shaped by social sciences that mimic the quantification of the natural sciences, motivated by a desire for scientific respectability. Such a scholarly paradigm is not ideal for the study of literary journalism, as it tends to exclude analysis and critical interpretation that makes no claim to being empirical. 
As to literary science journalism in particular, it is difficult to find any scholarly work on the form. Recently, some attention has been paid to the development of courses in science writing as literature, forming a part of science communication programmes (see Littmann 2005). However, I have not found many serious attempts to describe and understand the form, nor any examples of close analysis and interpretation of texts in science journalism that apply literary techniques. There is indeed a need for a closer examination of this form, as there is a need for an examination of literary journalism in general. As Lounsberry (1990) suggests, literary journalism has emerged as one of our contemporary literatures, its practice doing justice to the journalistic enterprise because it compellingly examines issues - philosophical, aesthetic and social - that are of profound concern to society and the individual.

\section{Theoretical Frame/Analytical Approach}

This article addresses questions such as: What are the characteristics of literary science journalism? What is it trying to achieve? How is the use of literary devices by science journalists enabled or constrained by different media formats and journalistic genres?

The article attempts to give some tentative answers to these questions by drawing on studies in "science and the media" and by examining excerpts from journalistic texts that apply literary devices. I concentrate on American science journalism, as I do in my doctoral thesis (Hornmoen 2003), because it is above all this area of journalism in this country that has been influenced by the literary, so-called "new journalism" of the 1960 s and 70 s.

My approach is not situated within the scholarly paradigm of social science as sketched out above. Rather, it is inspired by Critical Discourse Analysis (CDA) as practiced by Norman Fairclough (1992, 1995a, 1995b, 2001). According to Fairclough, discourse analysis is "an analysis of how texts work within sociocultural space" (1995b:7), and it may be regarded as "an attempt to show systematic links between texts, discourse practices, and sociocultural practices" (1995a: 17). Critical discourse analysis of journalism, thus, will try to understand how journalistic texts contribute to maintaining or changing institutional norms and practices, and how journalism is shaped by different social factors (whether wider sociocultural factors such as political pressures, or institutional factors such as professional ethics or genre codes). When studying science journalism, central questions will be: How do texts in science journalism create meaning? Which ideologies and power relations do the texts reflect (for instance between scientist sources, journalists and the audience)?

Rather than providing a formula for textual analysis, CDA may be regarded as a way of reflecting upon texts and their context and upon how meaning and different "ways of seeing" are constructed, reproduced and maintained in texts. In this preliminary article on literary science journalism, I must limit the scope of an analysis that ideally describes, interprets and explains different dimensions of discourse such as texts, discourse practice, sociocultural practice - and the relationship between them. Thus, my ambition is more modest. In the first part of the article, I wish to outline the characteristics of how literary science journalism articles are composed, and reflect on how these characteristics express and maintain a dominant role conception within the institution of science journalism.

Having outlined a dominant practice and ideological pattern, I analyse sample texts that may be indicative of how a different view of the science journalist's duties is emerging within the institution. However, the aim of such an analysis of a small number of 
discourse examples is certainly not to lay a foundation for generalizing about the functions, ideologies or possibilities of literary science journalism. Rather, the objective is to examine how the production of meaning in these texts is related to the type of media and the formats they are presented within.

In selecting the samples for the comparative analysis in the second part, I have been inspired by a strategy Fairclough recommends, namely to focus on "cruces" or critical features in texts. According to Fairclough, such cruces may be "sudden shifts of style" (1992: 230), and this applies to the samples I have chosen. When comparing the texts, I focus on some of the linguistic categories often studied in CDA, such as genre, discourse representation and modality.

\section{Characteristics of Literary Journalism}

What is literary journalism? For John Hartsock (1998), "literary journalism" refers to narrative nonfiction texts written largely by professional journalists who employ rhetorical techniques commonly associated with the realistic novel or short story. Historically, literary journalism is not a new phenomenon. Journalists such as Stephen Crane and Huchins Hapgood cultivated a literary form already during the $1890 \mathrm{~s}$. In the $20^{\text {th }}$ century, writers such as Ernest Hemingway, James Agee, John Hersey and Norman Mailer have contributed to shaping literary journalism.

But it was with the so-called New Journalism of the 1960s that writing inspired by literature expanded in parts of the press. The powerlessness that many journalists felt towards the events they were sent to report on within the rigid objective norm of the press was part of what gave rise to a form of journalism that experimented more with modes of presentation and did not hesitate to bring personal experiences into its accounts of reality. Widely circulated magazines such as Playboy, Esquire and The New Yorker now also allowed journalists sufficient time to try out literary techniques in their stories (Klit 1983, Hornmoen 1990).

For Tom Wolfe, commonly referred to as the leading spokesman for New Journalism, it is above all the use of literary techniques from realism that distinguishes the form from what roughly may be termed "conventional" journalism. The four techniques of the fictional literature of realism (applied by authors such as Honoré de Balzac and Gustave Flaubert in the $19^{\text {th }}$ century) that Wolfe (1975) - in a normative manner - identifies as the hallmark of the New Journalism are (in brief):

\section{Scene-on-scene Construction}

The writer is to compose the story by moving from scene to scene. The idea is to display events, settings and persons for the reader.

\section{Representation of Dialogue}

One is preferably to report dialogue in direct speech, literally and in as complete and revealing a fashion as possible.

\section{Representation of Characteristic Details}

The writer may, for instance, represent everyday gestures, habits, ways of dressing, interiors, different glances and ways of posing or walking. 


\section{Third-Person Point of View}

The technique is to present scenes through the eyes of a portrayed person, attempting to give the reader the feeling of experiencing "the emotional reality of the scene" in the way the depicted person did. ${ }^{1}$

One should emphasize that new journalists did not employ literary techniques in order to fictionalize journalism. On the contrary, the intent was to give a more complete account of reality than "conventional" journalism is able to provide. Application of literary devices requires a detailed and careful preliminary work. "Saturation reporting" is the expression Wolfe (1975:35) uses, referring to in-depth reporting that not only seeks to capture what is said and done, but also what is thought and felt, so that readers have access to the "inside" of the persons and events depicted. It is also termed "intensive reporting" (Murphy 1974), an activity that includes participant observation, in-depth interviews and extensive note taking.

Subjectivity is commonly considered a characteristic of this literary journalism (Murphy 1974). Some see its goal as an attempt to narrow the gap between subjectivity and a world reduced to a distant object by mainstream objectified journalism (Hartsock 1998). For a literary journalist, subjectivity implies a more active role in the composition of a report as compared to the more submerged role implicit in objective journalism, which emphasizes such values as neutrality and a balance between sources representing different opinions. Through the detailed characterization of persons and the composition of scenes and dialogues, the journalist makes her distinctive shaping consciousness known (see Weber 1974, Hartsock 1998). At the same time, the writer exposes her presence in the articles and stresses the importance of her own involvement in the subject being written about. This may be manifested by more frequent use of the personal pronoun "I" than in mainstream objective journalism.

Now, the editorial status of literary journalism in the US has been swinging, and it has not established itself as a dominant form in the American press since its heyday in the 1960s. Certainly, it is practiced by a great number of journalists in different types of publications. But it has also been accused of wavering between fantasy and fact, between fiction and a truthful representation of reality (see, e.g., Murphy 1974). Such a sceptical attitude towards the form is relatively widespread in an institution where the norm of objectivity is still "the key legitimating professional ethic" (McNair 1998:65).

\section{Literary Science Journalism - The Dominant Discourse}

However, it is worth noting how, towards the end of the previous century, different voices remark that it is in science journalism that the use of literary techniques now flourishes. The journalist and Pulitzer Prize winner John Franklin expresses this in the following way in an article from 1986:

We have to take readers into science the way John Steinbeck took them into Oklahoma.

Only by using emotion, and literary structure, can we send our truths in through the blind eye of the hurricane and calm it.

Science writers are moving in that direction, now, through dramatic non-fiction. (Franklin 1986) 
Less of a proclamation of a programme and more of a documentation of an existing trend is Ted Anton and Rick McCourt's collection of journalistic articles, The New Science Journalists (1995). According to the two editors, a new kind of science coverage emerged in American journalism in the late 1980s onwards into the 90s - both in magazines, daily newspapers and in books. This journalism is practiced by journalists who are more investigative and interpretive than they traditionally have been with regard to scientific matters, and some of them employ the narrative techniques characteristic of New Journalism.

Some of the compiled articles in the book testify to an extensive and thorough use of narrative devices, whether through a story structure based on models such as "the detective story", "a race against the clock", or something more closely resembling streams-of-consciousness. But one may question how representative a book that claims to gather "the best of science writing" is with respect to the use of literary techniques in science journalism. Furthermore, it is striking that some of the contributions in The New Science Journalists are excerpts from books, a medium that presumably provides different frames and possibilities of excelling in literary devices than what articles in the daily press - or even in popular science magazines - normally do.

What function does the use of literary devices in science journalism have? What purpose do they serve? Anton and McCourt speak emphatically about a new, insistent science journalism that explores scientific cultures, reveals dramatic conflicts between scientists and exposes not only successes, but also the failures of scientific research. But although some journalists have such goals and may realize them by applying narrative techniques in their stories, the function of literary techniques in science journalism thus far has mainly been pedagogical (see also Bennett 1986, Dornan 1990). Narrative devices are used to capture public attention and ultimately their purpose is to contribute to explaining and informing the public about science.

Statements by science journalists suggest that they can consider a literary form as appropriate for advancing the learning process - that is, an understanding of science in the public - without risking that readers will become bored or lose interest in the subject. Thus, according to Nathalie Angier, a merited science journalist in The New York Times:

You must teach without being didactic, that's where story comes in. (Angier in Anton \& McCourt 1995: 16-17)

Playing closer attention to the actual use of literary devices in this journalism, one notes that the magazine editor William Bennett, already in the 1980s, observed a characteristic structure in magazine stories about science. He registered the frequent occurrence of formulaic narrative leads in the articles, emphasizing action and a certain theatricality. In one magazine (Science 83), four articles begin in the following way:

Jim Curran is making one last phone call. His voice cracks...

Hans Goedicke is angry at George Michanowsky, but in a bemused way.

In the early afternoon on January 11, 1982, four Hopi Indian men walk into the Smithsonian's Museum of Natural History, a golden-domed science building...

Jim Anderson stands at the edge of a graveled hilltop with his eyes lifted and the fingers of one hand resting against his lower lip...

(from Bennett 1986: 125)

Similar dramatic leads may also be found in the feature articles of well-reputed popular science magazines today (e.g. Scientific American), as well as article leads in the 
science articles of the daily press. For instance, a clear line of relationship seems to connect the following leads, the first from a Pulitzer-Prize-winning article by Jon Franklin, the second one from a Pulitzer-Prize-winning article by Robert Capers and Eric Lipton. The last one is from the first article of a Pulitzer-Prize-winning series by Deborah Blum. In the leads of this journalism, there are quite a few chilly autumn and winter mornings, and scientists facing some crucial challenges.

In the cold hours of a winter morning Dr. Thomas Barbee Ducker, chief brain surgeon at the University of Maryland Hospital, rises before dawn. His wife serves him waffles but no coffee. Coffee makes his hands shake. (Franklin 1994: 28)

On a chilly autumn day in 1978, in an upstate New York factory town, Ronald R. Rigby Jr. stared at the glass that would dominate his life for the next three years. (In Anton \& McCourt 1995: 215)

On the days when he is scheduled to kill, Allen Merritt summons up his ghosts.

They come to him from the shadows of a 20-year-old memory. Eleven human babies, from his first year out of medical school. All born prematurely. All lost within one week when their lungs failed.

(...)

On this cool morning, he needs that memory. (In Anton \& McCourt 1995: 170)

These are openings that - despite their stereotypical form - have certain functions. By immediately attempting to draw the reader "into the middle of a plot", in medias res, the aim is apparently to create reader involvement in topics and subject matters commonly considered too complex to hold the reader's attention in the absence of such a narrative device. By concentrating on one or more persons, the journalist-narrator gives what is perceived as complex material a human face and enables reader identification with that which is being portrayed.

But it is characteristic of many articles covering science that the narrative is not continued throughout the article. As Bennett observes, what follows after the leads is not a sustained narrative: "Rather, the little story gets the reader into the tent; thereafter the exposition begins" (Bennett 1986: 125). One need not search long through the feature articles of a magazine like Scientific American, or the science section of The New York Times, before observing a typical structure in articles that employ narrative techniques. It is rather common to open with a narrative scene, which is followed by a more extensive part devoted to exposition. Characteristic of this part are attempts to describe and explain current research and its findings, before the article in some cases returns to the narrative towards the end, resulting in a circular composition.

When science journalism that applies literary devices appears in this way, it is reasonable to assume that this is partly due to the way in which quite a few science journalists view their own duties.

Now, there are clear indications of a markedly different role conception among American science journalists in the 1990s, as compared to what has been the dominant view since science journalism emerged as a profession in the 1930s. Some of the most qualified science journalists express the necessity of placing science in a broad societal context and of exploring how politics, ideology and culture influence perspectives and practice in research. In my doctoral thesis' critical discourse analysis of the central handbook A Field Guide for Science Writers (Blum \& Knudson 1997), I indicate how a "criti- 
cal" role conception is more pronounced among journalists who delimit their area of coverage roughly as "problems in society" (e.g., "toxics and risk reporting", "environmental writing", "public health and government", "infectious diseases") than it is among journalists who frame their area of coverage according to traditional disciplinary boundaries in the scientific institution (e.g., "physics", "astronomy") (Hornmoen 2003).

Still, a traditionally "dominant view of popularization" (see also Hilgartner 1990) has demonstrated a strong ability to survive within the institution of science journalism. According to this view, the journalist is a disseminator of scientific knowledge, engaged in improving the public understanding of an institution and activity in society that is considered to be poorly understood and appreciated. The scientific institution's efforts to improve the public understanding of science has traditionally been discernible in the role conception of science journalists (see Nelkin 1995). Journalists have willingly written - and still write - their articles in accordance with a model of communication whereby the scientist is viewed as the original and sole source of knowledge, the journalists as disseminators and the audience as receivers of this knowledge. The goal of the journalist's efforts in this perspective is maximum fidelity to the observations and exposition of the source, in other words, as little distortion as possible of what is viewed as the genuine first-hand knowledge of the scientist.

Add to this that on the science pages of the daily press "scientific findings at the frontier of research" have traditionally been considered selling news elements, with the latest publications of scientific journals viewed as the main reservoir for stories. "The most commonly understood duty of the science reporter is to keep readers abreast of important advances in scientific research," writes the veteran reporter and editor Boyce Rensberger (in Blum \& Knudson 1997: 9) in an article about covering science for newspapers.

Such frames and role conceptions set different conditions for the use of literary techniques than do articles commonly categorized as "literary journalism" or "new journalism”. In articles about New Journalism (e.g., Murphy 1974, Wolfe 1975), it is emphasized how this journalism uses the techniques of literary realism to depict and document different persons, social settings and groups, their everyday experiences and behaviour, their lifestyles, gestures, habits and status symbols. For Tom Wolfe, the basic unit of a reported narrative is not a collection of "facts" or "data" or a piece of information as such, but rather scenes involving people, groups or social settings (see Murphy 1974). More or less dramatic scenes, dense with action, are the main focus of much new journalism. Here a central role for the journalist is to be an active, participant observer of "the whole business of "the way we live now", as Wolfe expresses it (1975: 43).

The picture is not quite the same within the conventional frame for science journalists, as it is sketched out above. When a scientist's studies are the main focus, it is not primarily the journalists who are in a position that enables fundamental observations, or so-called eyewitness accounts. One may say that the real reporters of science are the scientists, or at least: they are in a position of being the reporters. The journalists are rather relegated to a role as referents of others' observations and studies, or arrangers of another person's work for the readers. This distribution of roles does not exactly create ideal conditions for absorbing literary journalism.

One solution for the journalist appears to be to try to enliven the story by observing the researcher or the researcher's object in different situations in order to create a narrative frame surrounding her pedagogical project. Some go even further in their attempt to create engaging prose and hide any traces of attempts to teach the public. Using narrative 
schemes such as "a scientist struggling with a puzzle", "a race against time" or "a race against another scientific institution" (see Hornmoen 2003), the journalist tries to create a more thorough narrative, emphasizing the research process. This is a narrative form that is seemingly true to the characteristic feature of science as a process whereby theories are continually modified. But in practice, this form rather tends to create an exaggeratedly heroic picture of science. Such stories preferably require a solution, for instance that something is discovered or revealed, if the reader is not to feel cheated (see Dornan 1990). And some specialist science journalists, who readily have adopted views and values that are common in the scientific community, may be reluctant to use a narrative form that creates an unrealistic picture of what science is able to achieve.

Thus, many of them stick to the semi-narrative and less absorbing form, a form that shows more restraint than a great deal of New Journalism. This science journalism does not demonstrate an equally intensive form of "saturation reporting". It is not characterized to the same degree by a subjective presence, and it does not use literary techniques to the same extent. In a journalism form that gives exposition substantial space, literary techniques often amount to use of metaphors, analogies and comparisons in order to improve the public understanding of science. There is nothing wrong with this, but it has a tendency to result in what Bennett described as a "stylistic monotony, a shallowness in the reporting, a lack of texture" (1986: 124).

\section{Versions of Karl Popper, Thomas Kuhn and Stephen Jay Gould}

Is there no alternative to semi-narrative, educational prose? As suggested, some of the contributions to Anton and McCourt (1995) show that there is. And although it barely represents science journalism in the mainstream, a more pronounced literary journalism is emerging and practiced among writers who seem to understand their task as something other than teaching and knowledge transmission and who may choose to work within media formats that to a larger extent allow for thorough literary science journalism. I shall shed some light on this by discussing extracts from the work of John Horgan, one of the science journalists who use literary techniques most extensively. Horgan is interesting for several reasons. His most subjective, literary and critical work was originally presented within the profile genre in a popular science magazine. Furthermore, he has adapted material from these profiles in the chapters of his book The End of Science (Horgan 1996). This enables a comparative analysis of excerpts from the original magazine versions and from the book versions.

Horgan is particularly well-known - and widely criticized - for his book The End of Science. In it he fosters and argues for his thesis that science has already generated the revolutions and made all the great discoveries that human technology and cognitive limitations will allow:

(...) science is unlikely to make any significant additions to the knowledge it already has generated (Horgan 1996: 16).

Horgan's thesis and book have provoked many scientists and sparked controversy, but it is not my intent to discuss these reactions or to assess his theory. Rather I wish to draw attention to some rather striking disparities in his literary journalism as it is practised in the magazine, on the one hand, and the book, on the other.

In his book, Horgan builds his arguments around interviews - or more precisely profiles - that were originally published in the profile pages of the popular science maga- 
zine Scientific American (hereafter SA). One should immediately emphasize that Horgan also in his magazine profiles uses literary techniques to a larger extent than what is common in the aforementioned, characteristic semi-narrative science journalism. As in the following excerpt from his profile of Karl Popper, the philosopher of science:

During one of his brief pauses for breath, I mention his assertion that a theory must be falsifiable to be considered scientific. Is this falsifiability theory, I ask him, falsifiable? Popper places his hand over mine and transfixes me with a radiant smile. "I don't want to hurt you," he says, his voice softening, "but it's a silly question."

Still smiling, he gently explains that "the function of falsifiability is to say whether a theory is scientific or not. My theory of falsifiability is certainly not scientific. It belongs to metascience." Popper used to banish students from his seminar for asking such an "idiotic" question, but he doesn't blame me for doing so; some other philosopher, he suggests, probably put me up to it. "Yes", I lie. (Horgan 1992: 20-21)

In the many scenes of his magazine profiles, Horgan allows space for dialogue and the recording of details (e.g., "places his hand over mine"), details that contribute to characterizing the person being portrayed. The writer's subjectivity is discernible through his presence and engagement in his subject matter. In this sense, the excerpt will supposedly look more like the dramatic non-fiction that Jon Franklin envisioned in the 1980s than the semi-narrative and educational reports typical of science journalism. Rather than rhetorically optimizing a one-way lecture made by a scientist - or in this case a philosopher of science - the literary techniques here contribute to a different kind of reader involvement. We are brought more closely in touch with the scientist behind the rational façade, catching a glimpse of him as a human being, a person with feelings, one who may even be represented as adopting a somewhat defensive stance in relation to his own theories.

It may seem paradoxical that Horgan sows the seeds of his subjective, literary and critical profiles in a magazine that in many ways is devoted to demonstrating the value of science and new developments in research and technology (see Lewenstein 1992). Now, one should note that SA is oriented towards an audience interested in science and that the journalist may assume that readers have some knowledge of basic scientific concepts, so that informing about and defining such concepts does not characterize the writing here as much as in the science articles of daily newspapers. But when Horgan presents journalism in SA that is markedly more literary and critical than the science journalism typical of the daily press, it is reasonable to assume that this involves his experimenting with the possibilities the profile genre offers.

What characterizes the profile as a journalistic genre? Melvin Mencher's influential textbook News Reporting and Writing (1991) proposes that the profile should be seen as a...:

...mini-drama, blending description, action and dialogue. Through the words and actions of the source, with some help from the reporter's insertion of background and explanatory matter, the character is illuminated. (Mencher 1991: 303)

Other textbooks to a larger degree accentuate the journalist's subjective involvement when writing within this genre. They point out how the task of the profile writer is not only to capture the characteristic traits and behaviour of a person, but also to actively 
shape the portrayal by her own efforts as a narrator and stylist. Such views are expressed, for instance, in the Norwegian textbook Portrett-intervju (Lamark 1995). According to its author, one of the objectives of the profile may be to enter into a duel with a person who holds controversial standpoints on certain matters. Another goal may be to challenge a person who stands at the frontier of a field, testing the depth of her commitment. It is not a goal of the profile to draw a one-sided positive picture, that is, an embellished portrait of the person being written about.

In other words, this is a genre that conventionally allows the writer larger latitude to participate and employ a personal voice than do most other genres in journalism. It admits greater equality between the journalist and the portrayed. For journalists who write about science or scientists, the profile provides possibilities for focusing on other sides of the subject than a news report normally would. Writing within this genre, one need not be so fixated on what science journalists tend to consider as necessary news pegs in their work, namely a fresh scientific discovery or a "ground-breaking" research result (Hornmoen 2003).

But even though such factors may contribute to explaining the subjectivity and literary flair in Horgan's magazine profiles, there is reason to point out that the adjusted profiles in the chapters of his book appear as even more dramatic, subjective and thoroughly literary. For instance, observe how he embroiders upon the episode with Popper:

It was time to launch my big question. Was his own falsification concept falsifiable? Popper glared at me. Then his expression softened, and he placed his hand on mine. "I don't want to hurt you," he said gently, "but it is a silly question." Peering searchingly into my eyes, he inquired whether one of his critics had persuaded me to ask this question. Yes, I lied. "Exactly," he said, looking pleased.

"The first thing you do in a philosophy seminar when somebody proposes an idea is to say it doesn't satisfy its own criteria. It is one of the most idiotic criticisms one can imagine!" His falsification concept, he said, is a criterion for distinguishing between empirical modes of knowledge, namely, science, and nonempirical ones, such as philosophy. Falsification itself is "decidably unempirical"; it belongs not to science but to philosophy, or "metascience," and it does not even apply to all of science. Popper was admitting, essentially, that his critics were right: falsification is a mere guideline, a rule of thumb, sometimes helpful and sometimes not.

Popper said he had never before responded to the question I had just posed. "I found it too stupid to be answered. You see the difference?" he asked, his voice gentle again. I nodded. The question seemed a bit silly to me, too, I said, but I just thought I should ask. He smiled and squeezed my hand, murmuring, "Yes, very good."

(Horgan 1996: 38-39)

Whereas this scene is introduced early on in the magazine profile, in the book it is placed towards the end of the profile of Popper, as a part of what appears to be a carefully planned dramaturgy. In the book version, the scene is represented as more dramatic by an extensive use of direct speech ("quotations") and dialogue. Greater attention is paid to details in Popper's behaviour. Popper is portrayed as more hasty and biting in his comments than in the magazine version. The profile creates a picture of a less likeable, more aggressive and incalculable personality. At the same time, the narrator's 
presence is more distinct, to a larger degree appearing as a participating actor in the scenes of the text. After the extracted scene, the journalist-narrator in the book thus follows up by posing critical and 'unpleasant' questions to the interviewee. In the magazine profile, however, the equivalent scene is succeeded by words suggesting a far more humble narrator:

I should have known better than to try to trip up Karl Popper. For more than 70 years, he has been debating this century's greatest ideas with this century's greatest minds. (Horgan 1992:20)

Particularly striking is how the narrator emerges as a markedly more authoritative interpreter of Popper's statements in the book version. Whereas the magazine version hardly includes any narrator comments evaluating Popper's theories, the situation is different in the book. For instance, early on in the chapter, the narrator's consideration of Popper's views gives rather clear guidance on how one should understand Popper's statements in this text:

As I began to question Popper about his views, it became apparent that his skeptical philosophy stemmed from a deeply romantic, idealized view of science. (Horgan 1996: 36)

Thus, the book chapter to a larger extent includes evaluations and uses literary techniques than does the magazine profile. Employment of these techniques also serves a somewhat different purpose than in the magazine article. The portraying of Popper as such is the main objective in the magazine profile: By using techniques typical of literary realism, the writer tries to expose him as he "really" is, capturing characteristic traits by observing and describing his gestures, his thoughts and ways of expressing himself. In the book version, the more extensive use of literary techniques has a supplementary function. Here, the portrayal above all serves to illustrate the paradoxes and shortcomings of Popper's theory in a way that substantiates Horgan's thesis about The End of Science, or more precisely in this case: The end of the philosophy of science.

Other profiles in the book chapters bear witness to how this medium provides the journalist with greater authority and possibility of playing out literary devices than does the magazine. A case in point is the profile of the historian/philosopher of science Thomas Kuhn. In it, space is provided for a different representation than in the magazine version (1991) of what Kuhn - in indirect discourse - describes as an epiphany, that is, a sudden experience of insight. At Harvard in 1947, he had an experience that he felt would shape his view of science. In the book, the narrator returns to this experience with an ironic attitude that does not appear to the same extent in the magazine profile:

Kuhn has tried, throughout his career, to remain true to that original epiphany he experienced in his dormitory at Harvard. During that moment Kuhn saw - he knew! - that reality is ultimately unknowable; any attempt to describe it obscures as much as it illuminates. (Horgan 1996:47)

Undoubtedly, the second sentence is an elegant formulation. It contains an element of socalled free indirect discourse by representing a person's thoughts or speech without introducing or qualifying it by expressions such as "He said that..." The narrator's report and direct speech are mixed in such a way that the boundaries between speech and thought are erased. In the case above, the representation of Kuhn's exclamation - or rather, his sudden experience (he knew!) - serves to mimic his epiphany. This technique invites the 
reader to see and experience reality through the person being portrayed. Writers considered to be new journalists have applied this technique, drawing on both the realism of the $19^{\text {th }}$ century and the modernistic novels of the $20^{\text {th }}$ century (see Wolfe 1975 ).

Worth noting is how the technique enables the narrator to express either a sympathizing or a mocking identification with the thoughts of the portrayed persons. Above, we have an example of what the narratologist Dorrit Cohn (1978) perceives as an ironic narration of a person's thoughts. Horgan's narration is somewhat more ridiculing here than in the magazine version, one main objective of his book apparently being to uncover paradoxes and flaws in the theories of his 'victims'. The technique undoubtedly allows Horgan to express an attitude towards the thoughts of those portrayed and contributes in this way to the impression of a strongly subjective form of journalism.

Differences between the book and magazine representations may not only be traced when the people being portrayed are philosophers of science. They also distinctively emerge when the profiles are of researchers as such or, in other words, of scientists. One case in point: Both in the magazine profile and in the book, the biologist (or paleontologist) Stephen Jay Gould is confronted with a question concerning his theory of evolution as a random and discontinued process as opposed to a gradual one. The journalist has noticed that whereas Gould in 1972 had called his theory an "alternative" to Darwin's theory of a gradual evolution, he later switched to using the term "a complement". Horgan asks whether or not the change in vocabulary may be understood as conceding Darwin's supremacy in the understanding of evolution. My point here is that Horgan's different ways of representing Gould's answers in the magazine profile and the book contribute to creating a somewhat different profile of the man.

In the magazine, Horgan writes:

He then proceeds to argue that alternative and complement do not have such different meanings. "If you claim something is an alternative, that doesn't mean it operates exclusively," he says. "I think punctuated equilibrium has an overwhelmingly dominant frequency in the fossil record, which means gradualism exists, but it's not really important in the overall pattern of things." (Horgan 1995:27)

On the other hand, in the book's more scenic composition, Gould is given more space to express his reactions to the question in direct speech:

(...) Gould proceeded to argue that alternative and complement do not really have such different meanings.

"Look, by saying it's an alternative, that doesn't mean that the old kind of gradualism doesn't exist. See, that's another thing I think people miss. The world is full of alternatives, right? I mean we've got men and women, which are alternative states of gender in Homo sapiens. I mean if you claim something is an alternative, that doesn't mean it operates exclusively. Gradualism had pretty complete hegemony before we wrote. Here's an alternative to test. I think punctuated equilibrium has an overwhelmingly dominant frequency in the fossil record, which means gradualism exists but it's not really important in the overall pattern of things." (Horgan 1996: 124)

More phrases typical of spoken language are included here than in the magazine profile. They contribute to representing Gould as less of a distanced authority figure and more of a present, emotionally involved person on the same level as "other human be- 
ings". Phrases such as "look", "see", "I mean", and "right" can be understood as signs of so-called expressive modality (Fairclough 2001, Vagle 1995), that is, as expressions of how the speaker shows that he pledges himself to the truthfulness or probability of the referential content of his utterance. As I interpret the phrases in this context, they do not function so much to strengthen the authority of what the speaker is expressing, as they suggest the speaker's personal involvement in the subject. They signal a more "human" reaction and may be interpreted as contributing to strengthening the authority of Horgan's claims about the limitations of the theories of the person he is portraying.

\section{Concluding Remarks}

By comparing excerpts from John Horgan's profiles as they are presented in "original" versions in a popular science magazine with reworked versions as presented in a book, I have indicated how the different media and formats provide different frames for the journalist's portrayal of his subjects and his possibility of expressing a subjective and independent view on them. In the book version, Horgan to a greater extent displays a literary journalism.

The different persons portrayed by Horgan tend to exhibit some striking similarities in the book version, as figures with partly comical or ludicrous traits. One may question whether Horgan, with his writing style and use of literary techniques, tends to reflect the type of comical figures in a non-fictional, literary tradition to the same degree that he reflects the scientists he portrays. In any case, the book version evidently gives the journalist greater authority and power: In this medium and format, he is no longer "only" a reporter, he can act or pose in a role as an omniscient narrator ${ }^{2}$ or a philosopher. In this position, he uses his craft of journalistic reporting and portraying to confirm his theory that science has reached some kind of an end.

Now, the samples from Horgan's work do not provide a ground for generalizations about the different conditions, functions and possibilities of literary science journalism in books as opposed to magazines. But when it is in the book medium that Horgan more thoroughly displays his literary journalism, marks a subjective and interpretive presence and covers his subject in depth, this is in accordance with a tendency in New Journalism. As James E. Murphy emphasizes in his critical discussion of New Journalism:

The writer's immersion of himself in his subject is more apparent in lengthier accounts, and that is why much New Journalism, especially when at book length, manifests this characteristic more clearly than most in-depth reporting. (Murphy 1974: 35)

As I have suggested, the genre "the magazine profile" also seems to allow the journalist greater freedom to express his views and use literary devices compared to other genres in popular science magazines or more pronounced news media such as the daily press. In the latter, I have suggested how literary journalism is commonly reduced to a semi-narrative form. The educational purpose of these semi-narratives is to improve public understanding of the scientific knowledge that scientist sources possess. This is in accordance with a traditionally dominant role conception among science journalists.

When the journalist John Horgan "restrains himself" and draws somewhat more sober and respectful scientist profiles in the magazine than in his book, this may be partly due to the frames or ideology of the magazine. After all, he is writing in a magazine that, 
according to Lewenstein, has traditionally been viewed as "a monument to the vision of science as the saviour of the world" (1992:51).

Personally, I welcome all journalistic contributions that can provide nuances to a picture of science as the saviour of the world, whether in newspapers, magazines, books or television and radio. And as my discussion has suggested, journalists may also achieve this by using literary devices in their stories.

\section{Notes}

1. In discourse analysis, this way of representing discourse or speech is commonly referred to as "free indirect style" or "free indirect discourse/speech" (see, e.g., Fairclough 1995, Waugh 1995). Free indirect discourse typically combines elements of direct speech with elements of the narrator's report and blurs the distinction between speech and thought.

2. In narrative theory and criticism, the term "omniscient narrator" commonly refers to fictional narrative in which the narrator knows more than the character (see, e.g., Genette 1980). The omniscient narrator knows "everything", gives the reader information and may reveal the motivations, thoughts and feelings of the characters.

\section{References}

Anton, T., McCourt, R. (1995) (ed.) The New Science Journalists. New York: Ballantine Books.

Bennett, W. (1986) 'The Medium Is Large, but How Good Is the Message?', in Friedman, S.M., Dunwoody, S., Rogers, C.L. (1986) Scientists and Journalists. Reporting Science as News. New York: The Free Press.

Blum, D., Knudson, M. (1998) (ed.) A Field Guide for Science Writers. New York: Oxford University Press.

Cohn, D. (1978) Transparent Minds: Narrative Modes for Presenting Consciousness in Fiction. Princeton University Press.

Dornan, C. (1990)'Some Problems in Conceptualizing the Issue of 'Science and the Media', Critical Studies in Mass Communication 7: 48-71.

Fairclough, N. (1992) Discourse and Social Change. Cambridge: Polity Press

Fairclough, N. (1995a) Media Discourse. London: Edward Arnold

Fairclough, N. (1995b) Critical Discourse Analysis. London: Longman

Fairclough, N. (2001) Language and Power - Second Edition. London: Longman.

Franklin, J. (1986)'Humanizing Science Through Literary Writing', in Friedman, S.M., Dunwoody, S., Rogers, C.L. (1986) Scientists and Journalists. Reporting Science as News. New York: The Free Press.

Franklin, J. (1994)Writing for Story. New York: Plume/Penguin.

Genette, G (1980) Narrative Discourse. An Essay in Method. New York: Cornell University Press.

Hartsock, J. (1998)'The Critical Marginalization of American Literary Journalism', Critical Studies in Mass Communication 15: 61-84.

Hilgartner, S. (1990) 'The Dominant View of Popularization: Conceptual Problems, Political Uses', Social Studies of Science, 20, 519-39

Horgan, J. (1991) 'Profile: Reluctant Revolutionary', Scientific American, May 1991: 14-15.

Horgan, J. (1992) 'The Intellectual Warrior. Profile: Karl R. Popper', Scientific American, November 1992: 20-21.

Horgan, J. (1995) 'Escaping in a Cloud of Ink. Profile: Stephen Jay Gould', Scientific American August 1995: 26-27.

Horgan, J. (1996) The End of Science. Facing the Limits of Knowledge in the Twilight of the Scientific Age. Reading: Helix Books.

Hornmoen, H. (1990) 'Særtrekk ved amerikansk 'New Journalism' med særlig vekt på Tom Wolfes tekster' [Characteristics of American New Journalism, with an emphasis on Tom Wolfe's texts.] Semester paper for the Master's Degree in Comparative Literature, University of Oslo.

Hornmoen, H. (2003) Forskningsjournalistikk i en brytningstid. Kritisk diskursanalyse av amerikansk "science journalism" på 1990-tallet. [Science journalism in a period of transition. Critical discourse analysis of American science journalism in the 1990's.] PhD thesis. Acta Humaniora nr. 172, Unipub: University of Oslo.

Klit, J. (1983) Journalistikk og Fiktion. [Journalism and Fiction.] København: Levende Billeder. 
Lamark, H. (1995) Portrett-intervju som metode og sjanger. [The profile interview as a method and a genre.] Fredrikstad: Institutt for Journalistikk.

Lewenstein, B.V. (1992)'The Meaning of 'Public Understanding of Science' in the United States after World War II", Public Understanding of Science 1(1) 45-68.

Littmann, M. (2005) Courses in Science Writing as Literature', Public Understanding of Science 14: 103112.

Lounsberry, B. (1990) The Art of Fact: Contemporary Artists of Nonfiction. New York: Greenwood Press.

McNair, B. (1998) The Sociology of Journalism. London: Arnold

Mencher, M. (1991) News Reporting and Writing (5 $5^{\text {th }}$ ed.). Wm.C. Brown Publishers.

Murphy, J.E. (1974) 'The New Journalism: A Critical Perspective', Association for Education in Journalism.

Rensberger, B. (1997)'Covering Science for Newspapers', in Blum, D., Knudson, M. (1997): A Field Guide for Science Writers. New York: Oxford University Press.

Vagle, W. (1995) 'Kritisk tekstanalyse' [Critical text analysis] in Svennevig, J., Sandvik, M., Vagle, W., Tilnaerminger til tekst. Modeller for språklig tekstanalyse, [Approaches to texts. Models for linguistic textual analysis.] Oslo: LNU and Cappelen.

Waugh, L.R. (1995)'Reported Speech in Journalistic Discourse: The Relation of Function and Text', Text 15 (1): 129-173.

Weber, R. (1974) (ed.) The Reporter as Artist. New York: Hastings House.

Wolfe, T. (1975) The New Journalism, with an anthology edited by Tom Wolfe and E.W. Johnson. London: Picador. 
